See Article page 155 .

\section{Commentary: Risk of overlapping surgery in cardiac surgery? Much ado about nothing}

\author{
Ahmet Dolapoglu, MD, ${ }^{\mathrm{a}}$ and \\ Joseph S. Coselli, MD ${ }^{\mathrm{b}, \mathrm{c}, \mathrm{d}}$
}

Overlapping surgery is a relatively new term for physicians, patients, and health policy agencies to describe a longstanding practice that has been fairly common in cardiothoracic surgery: the practice of running 2 operative rooms. In 2015, this concept gained wide attention after an exposé was published by the Boston Globe Spotlight Team regarding potential risks and lack of patient awareness of the practice ${ }^{1}$; soon thereafter, publications regarding overlapping surgery followed from orthopedic and other surgeons, some focusing on its controversy and ethics. ${ }^{2-5}$ Overlapping surgery is described as the practice of the primary responsible surgeon participating in another operation after critical portions of the first operation are completed; typically, this is done with the understanding that there is no need for the primary responsible surgeon to return to the first operation. Usually, the primary responsible surgeon is defined as the surgeon who performs all critical parts of the procedure and is always available to return the operating room if needed. Although there is no formal definition of the "critical" components of a procedure, these are generally considered to be those portions of the operation that require the surgeon's specific expertise.

\footnotetext{
From the ${ }^{a}$ Department of Cardiovascular Surgery, Balikesir University Medical School, Balikesir, Turkey; ${ }^{\mathrm{b}}$ Division of Cardiothoracic Surgery, Michael E. DeBakey Department of Surgery, Baylor College of Medicine; 'Department of Cardiovascular Surgery, Texas Heart Institute; and ${ }^{\mathrm{d}} \mathrm{CHI}$ St Luke's Health-Baylor St Luke's Medical Center, Houston, Tex.

Disclosures: Dr Coselli consults for, receives royalties and a departmental educational grant from, and participates in clinical trials for Terumo Aortic; consults and participates in clinical trials for Medtronic, Inc, and W.L. Gore \& Associates, Edwards Lifesciences, and Abbott Laboratories; and serves as a co-investigator for CytoSorbents. Dr Dolapoglu has nothing to disclose with regard to commercial support.

Received for publication Dec 16, 2019; revisions received Dec 16, 2019; accepted for publication Dec 16, 2019; available ahead of print Jan 7, 2020.

Address for reprints: Joseph S. Coselli, MD, Michael E. DeBakey Department of Surgery, Baylor College of Medicine, One Baylor Plaza, BCM 390, Houston, TX 77030 (E-mail: jcoselli@bcm.edu).

J Thorac Cardiovasc Surg 2021;162:165-6

0022-5223/\$36.00

Copyright (C) 2020 by The American Association for Thoracic Surgery

https://doi.org/10.1016/j.jtcvs.2019.12.054
}

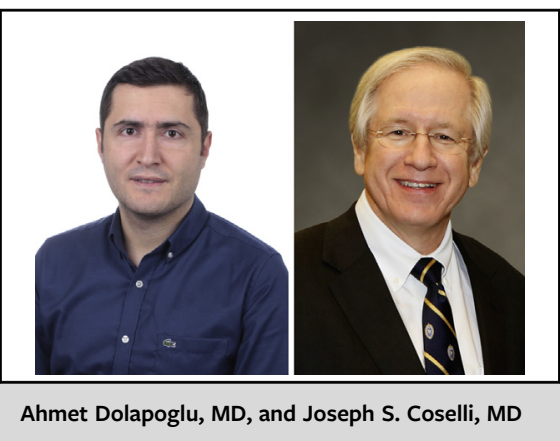

\section{CENTRAL MESSAGE \\ Overlapping surgery has been a mainstay of complex cardiac repair since the legendary era of DeBakey, Cooley, and Crawford; suggestions that this practice in- creases risk may be much ado about nothing.}

The American College of Surgeons has indicated that overlapping surgery is an acceptable approach to managing operative repair as long as patients are informed of the practice. In contrast, concurrent surgery (participating in 2 or more surgical procedures in which some or all critical portions are performed simultaneously) is deemed an inappropriate practice by the American College of Surgeons. A recent meta-analysis of 14 studies of overlapping surgery (including neurologic, thoracic, cardiac, hip, knee, and other operations) found no association with increased risk of early mortality or morbidity. ${ }^{6}$

Generally, overlapping surgery is framed within the context of elective repair. Potential benefits of overlapping surgery include the better use of operating room resources, facilitating greater volumes of complex surgery, reducing waiting time for specialty repairs, and a reduction of costs associated with academic medical institutions. In addition, overlapping surgery provides crucial learning opportunities for surgical residents during their training. However, a recent high-profile study analyzed the effects of overlapping in 8 different surgical procedures; an adjusted analysis showed that overlapping increased operative risk for coronary artery bypass grafting but not for the other 7 procedures (all noncardiac). ${ }^{7}$ This finding raised concern that although overlapping surgery may be harmless in most specialties, perhaps cardiac surgery is negatively affected by this practice. 
In this issue of the Journal, Glauser and colleagues ${ }^{8}$ have focused on the safety of overlapping in cardiac surgery (which they defined as including open and endovascular procedures as part of cardiac or aortic repair); in addition, they assessed the effect of the timing of overlap. The authors used a robust matching approach (coarsened exact matching) to mitigate the individual risk profile of patients, resulting in 984 matched pairs of patients with and without surgical overlap. The results showed that overlapping cardiac surgery was no different from nonoverlapping surgery with regard to early mortality and morbidity, as well as short-term readmission and the need for reoperation. This study also indicated that the timing of the overlap (beginning or end of the procedure) had no effect on the outcomes studied.

The authors fill a gap in that the impact of overlap has not been thoroughly investigated in cardiac surgery. Few patient-matched studies of overlap have been publishednot only in cardiac surgery but in any type of surgery. The mastery of complex surgery depends on an active mentorship that can expose trainees to many cases within the relatively short window of supervised surgical training. Overlapping surgery has been a mainstay of complex cardiac operations since the legendary era of DeBakey, Cooley, and Crawford; suggestions that this practice increases operative risk may be much ado about nothing.

\section{References}

1. Abelson J, Saltzman J, Kowalczyk L, Allen S. Clash in the name of care. Boston Globe. October 25, 2015. Available at: https://apps.bostonglobe.com/spotlight/ clash-in-the-name-of-care/story/. Accessed December 16, 2019.

2. Levin PE, Moon D, Payne DE. Overlapping and concurrent surgery: a professional and ethical analysis. J Bone Joint Surg Am. 2017;99:2045-50.

3. Mello MM, Livingston EH. The evolving story of overlapping surgery. JAMA. 2017:318:233-4.

4. Zhang AL, Sing DC, Dang DY, Ma CB, Black D, Vail TP, et al. Overlapping surgery in the ambulatory orthopaedic setting. J Bone Joint Surg Am. 2016;98: $1859-67$.

5. Zygourakis CC, Sizdahkhani S, Keefe M, Lee J, Chou D, Mummaneni PV, et al. Comparison of patient outcomes and cost of overlapping versus nonoverlapping spine surgery. World Neurosurg. 2017;100:658-64.e8.

6. Gartland RM, Alves K, Brasil NC, Mossanen M, Mort E, Wright CD, et al. Does overlapping surgery result in worse surgical outcomes? A systematic review and meta-analysis. Am J Surg. 2019;218:181-91.

7. Sun E, Mello MM, Rishel CA, Vaughn MT, Kheterpal S, Saager L, et al. Association of overlapping surgery with perioperative outcomes. JAMA. 2019;321: 762-72.

8. Glauser G, Goodrich S, McClintock SD, Szeto WY, Atluri P, Acker MA, et al. Association of overlapping cardiac surgery with short-term patient outcomes. J Thorac Cardiovasc Surg. 2021;162:155-64.e2. 